Document downloaded from:

http://hdl.handle.net/10251/122918

This paper must be cited as:

Corma Canós, A.; Sauvanaud, LL.; Mathieu, Y.; Al-Bogami, S.; Bourane, A.; Al-Ghrami, M. (2018). Direct crude oil cracking for producing chemicals: Thermal cracking modeling. Fuel. 211:726-736. https://doi.org/10.1016/j.fuel.2017.09.099

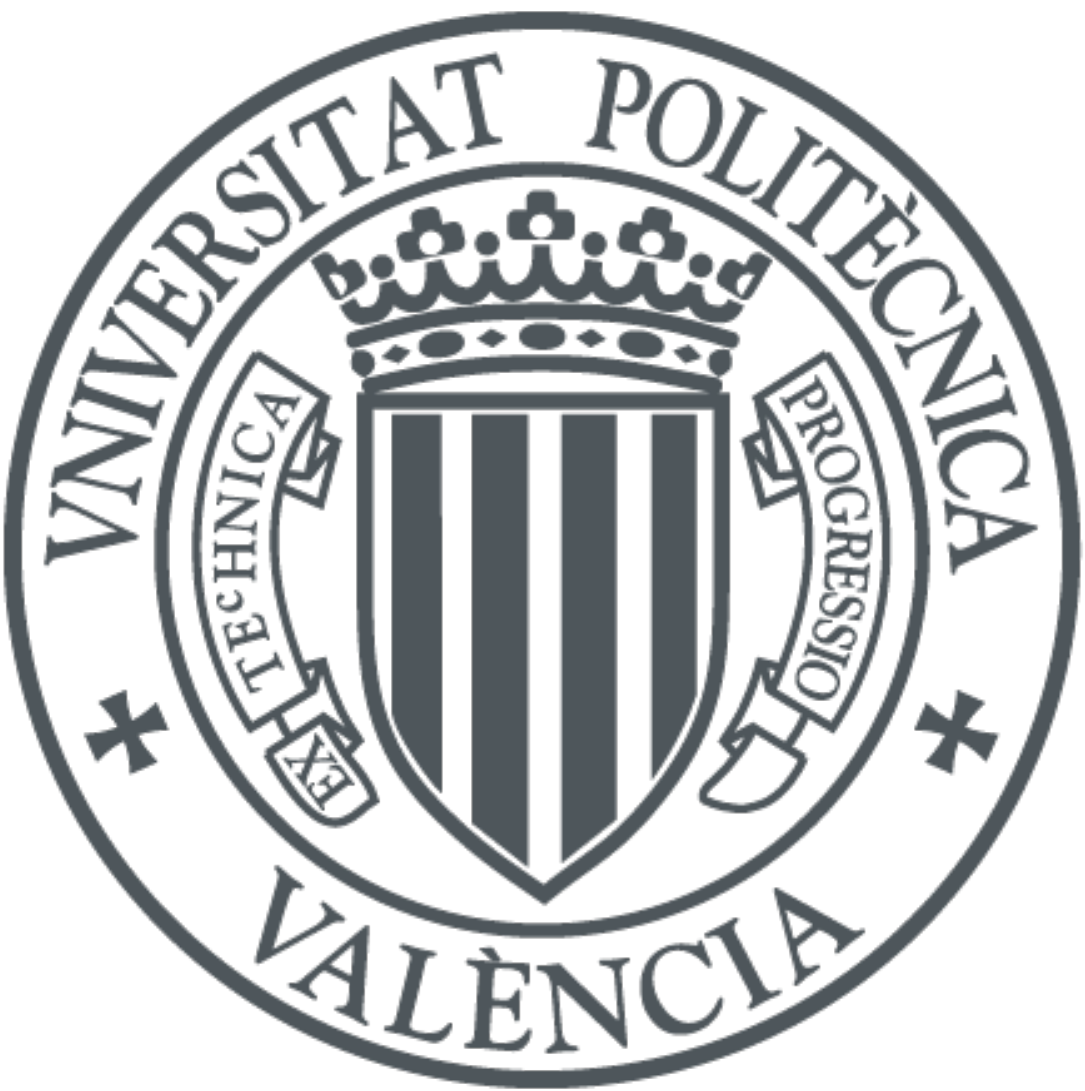

The final publication is available at

http://doi.org/10.1016/j.fuel.2017.09.099

Copyright Elsevier

Additional Information 


\section{Direct Crude Oil Cracking for producing chemicals: Thermal Cracking Modeling}

Avelino Corma ${ }^{1, *}$, Laurent Sauvanaud ${ }^{1}$, Yannick Mathieu ${ }^{1}$, Saad Al-Bogami ${ }^{2}$, Abdennour Bourane2, Musaed Ghrami²,

${ }^{1}$ Instituto de Tecnología Química, Universitat Politècnica de València-Consejo Superior de Investigaciones Científicas, Avda. de los Naranjos, s/n; 46022 VALENCIA, SPAIN

${ }^{2}$ Research and Development Center, Saudi Aramco, P.O. Box 62 Dhahran 31311, Saudi Arabia.

* Corresponding author.

E-mail address: acorma@itq.upv.es 


\section{Abstract}

The direct cracking of crude oil is an interesting option for producing cheaply large amounts of petrochemicals. This may be carried out with catalyst and equipment similar to that of catalytic cracking, but at a temperature range between that of standard catalytic cracking and steam cracking. Thermal cracking will play a role in the conversion, but is rarely disclosed in experimental or modeling work. Thus, a crude oil and its fraction were thermally cracked and the products yields were modeled using a 9 lumps cracking scheme. It was found that heavy fraction cracks twice as fast as diesel fraction and ten times faster than gasoline fraction, with activation energies in the $140-200 \mathrm{~kJ} / \mathrm{mol}$. Selectivity to ethylene, propylene and butenes were found similar in the operating range explored.

\section{Key words}

Crude oil thermal cracking modeling

\section{Highlights}

- Thermal cracking of crude oil and its fractions was performed in the 560-640ㄷ temperature range.

- Yields of olefins above 20 wt\% could be obtained directly from crude oil, maintaining low amounts of dry gas and coke.

- Thermal cracking of the crude oil and its fractions was modeled

\section{Graphical Abstract}






\section{Introduction}

Most petrochemical feedstocks, namely light olefins (ethylene, propylene, butenes, butadiene) and aromatics (benzene, toluene, xylenes) are produced today as valuable byproducts from petroleum refining. Their markets are expanding and new producing technologies have to be implemented [1]. A large part of the olefin production is ensured today through steam crackers [2], where the ratio between the two main olefins, ethylene to propylene, is not very flexible and usually produces more ethylene than propylene. As a consequence, propylene has been increasingly sourced from catalytic cracking, and on-purpose propylene processes such as propane dehydrogenation and olefin metathesis. In terms of catalytic cracking, a number of high temperature and high catalyst to oil ratio processes have been developed [3]-[6]. As a refinery product, petrochemicals production is dependent on the refinery feedstock. Crude oil would be an ideal feedstock for directly producing olefins and aromatics. Then, direct steam cracking of crude oil has to deal with coking issues, which can be tackled by separating the heavy fraction or using solid heat carriers to retain coke [7]-[9]. Also, the limited flexibility in the ratio of the produced olefins calls for a different process, which could be inspired from Fluid Catalytic Cracking process [10].

Numerous models have been used to model catalytic cracking of Vacuum Gas Oil [11]-[17], and some were directed to high temperature cracking for olefins dedicated processes [18]-[21]. Lumps are usually used for modeling distillates (gasoline and higher boiling point compounds), while the gas fraction description may be more detailed, with the sought olefins sometimes modeled as a separate component. In most of the models related to catalytic cracking, thermal cracking is not modeled, as the thermal contribution to the final yields is considered as negligible compared to the much faster catalytic process. While this is a very legitimate assumption for traditional catalytic cracking, which operates at temperatures below $550^{\circ} \mathrm{C}$, this is no longer accurate when the temperature increases above $600^{\circ} \mathrm{C}$, where the thermal contribution begins to be important [22]. A number of models were developed for steam cracking of light feeds and naphthas, with a great detail of reaction scheme and resulting gas compositions for a wide range of feeds, for example the SPYRO model [23]. Models for (thermal) pyrolysis of crude oil that include the vacuum gas oil fraction were however not reported, as this feed is not used in steam cracking due to coking issues. We also sought for a model easily compatible with simple catalytic cracking models.

By keeping in mind a process that would involve the direct high temperature cracking of crude oil using a solid carrier/catalyst to produce olefins, while removing coke, the current study reports the thermal cracking of a crude oil, in a temperature range that covers from high end catalytic cracking $\left(560^{\circ} \mathrm{C}\right)$ to high temperature olefins oriented processes $\left(640^{\circ} \mathrm{C}\right)$. The full crude oil was processed. After splitting into a light and a heavy fraction, the response to thermal cracking of these fractions was also examined. A 9 components model was then developed to describe thermal cracking.

\section{Experimental}

\subsection{Materials}




\section{Solid heat carrier}

An inert solid was used as a heat carrier in the setup to provide heat for vaporization and thermal cracking. While the wall may transfer some heat to the gas media, it is preferable to have a solid in the unit acting as thermal mass and providing efficient heat transfer for feed vaporization and compensate for heat of reaction. Sand is often used, but has poor flowing properties. In our case a solid was prepared from an Equilibrium catalyst (E-Cat) which was impregnated with $\mathrm{Na}$ and then steamed at $900^{\circ} \mathrm{C}$ for $10 \mathrm{~h}$. The obtained particles have shown a surface area below $1 \mathrm{~m}^{2} / \mathrm{g}$ and no acidity could be measured through pyridine adsorption. Yet the solid retained the microsphere shape and density of an equilibrium catalyst, which allowed smooth flowing through the unit. Inertness of the solid was checked comparing the obtained activity with that of carborundum in a Microactivity test at 545ㄷ using a standard VGO. Identical results were obtained for the two solids: very low conversion due to thermal cracking.

\section{Feed characterization}

The properties of the crude oil used in this study are listed in Table 1. The crude was further fractionated into a light and a heavy fraction, with a cut point set at $350^{\circ} \mathrm{C}$. Properties of the crude oil fractions are listed in Table 2 and Table 3.

Table 3As for crude oil, the boiling point curve was determined by Simulated Distillation (SIMDIS) following ASTM D-2887 specifications. The relative amount of the fractions in the crude oil was determined as $61 \mathrm{wt} \%$ light fraction and $39 \mathrm{wt} \%$ of heavy fraction. Some butane present in the crude oil was lost during the distillation and as a result gasoline composition in the light cut is slightly different from the gasoline composition in the crude oil. Analysis showed that $\mathrm{n}$ butane for crude oil is about $0.9 \mathrm{wt} \%$ and $0.3 \mathrm{wt} \%$ for light fraction.

Table 1. Properties of the crude oil

\begin{tabular}{|c|c|c|c|}
\hline $\begin{array}{l}\text { Den } \\
\text { Sulfu } \\
\text { CCR }\end{array}$ & $\begin{array}{l}@ 15 \\
\text { wt\%) } \\
\%)\end{array}$ & $\left.\mathrm{g} / \mathrm{cm}^{3}\right)$ & $\begin{array}{l}0.828 \\
1.1 \\
1.4\end{array}$ \\
\hline Disti & ion $\mathrm{Cl}$ & (D-11 & $\left.\mathrm{DIS},{ }^{\circ} \mathrm{C}\right)$ \\
\hline 10 & 50 & 90 & \\
\hline 134 & 284 & 487 & \\
\hline SIMI & cut, $v$ & & \\
\hline Gasc & (ibp & $6 \div C)$ & 38.8 \\
\hline Dies & $216-3$ & & 30.6 \\
\hline Bott & $5(35$ & & 30.6 \\
\hline
\end{tabular}


Table 2. Properties of the crude oil light fraction

\begin{tabular}{|c|c|c|c|}
\hline \multicolumn{3}{|c|}{$\begin{array}{l}\text { Density @15으 }\left(\mathrm{g} / \mathrm{cm}^{3}\right) \\
\text { CCR (wt\%) }\end{array}$} & $\begin{array}{l}0.750 \\
-\end{array}$ \\
\hline \multicolumn{4}{|c|}{ Distillation curve (D-1160 from SIMDIS, ㅇ } \\
\hline 10 & 50 & 90 & \\
\hline 122 & 215 & 299 & \\
\hline \multicolumn{4}{|c|}{ SIMDIS cut, wt\% } \\
\hline \multicolumn{3}{|c|}{ Gasoline (ibp-216으) } & 58.2 \\
\hline \multicolumn{3}{|c|}{ Diesel (216-359으) } & 41.8 \\
\hline \multicolumn{3}{|c|}{ Bottoms (359-fbp) } & 0.0 \\
\hline
\end{tabular}

Table 3. Properties of the crude oil heavy fraction

\begin{tabular}{|c|c|c|c|}
\hline \multicolumn{3}{|c|}{$\begin{array}{l}\text { Density @15으 }\left(\mathrm{g} / \mathrm{cm}^{3}\right) \\
\text { CCR (wt\%) }\end{array}$} & $\begin{array}{l}0.920 \\
3.9\end{array}$ \\
\hline \multicolumn{4}{|c|}{ Distillation curve (D-1160 from SIMDIS, ㅇ } \\
\hline 10 & 50 & \multicolumn{2}{|l|}{90} \\
\hline 391 & 458 & \multicolumn{2}{|l|}{590} \\
\hline \multicolumn{4}{|c|}{ SIMDIS cut, wt\% } \\
\hline \multicolumn{3}{|c|}{ Gasoline (ibp-216C) } & 0.0 \\
\hline \multicolumn{3}{|c|}{ Diesel (216-359으) } & 6.3 \\
\hline \multicolumn{3}{|c|}{ Bottoms (359-fbp) } & 93.7 \\
\hline
\end{tabular}

\subsection{Cracking setup}

Hardware and detailed operation of the Microdowner unit has been described previously [24][25]. Main features of the unit comprises a solid preheater where said solid is stored before the test, a once-through reactor where the feed and the preheated solid are fed continuously during the test while their residence time is very short, ranging from 0.3 to 5 seconds, and a separator which separates hydrocarbons and collect spent solid for further regeneration and coke determination. The unit simulates a steady state regime during the length of the test, which usually takes between one and two minutes. The solid separated from the reaction products is continuously stripped during the reaction and for 60 seconds more after the end of the reaction. Liquids and gaseous products are recovered by cold traps and water displacement burette while the coke deposited on the solid is burned in-situ after the test with a $500 \mathrm{ml} / \mathrm{min}$. of air at $850 \mathrm{~K}$ during $3 \mathrm{~h}$. Alternatively, the coked solid can be withdrawn from the unit after the stripping step, and coke is determined by Elemental Analysis. A flow of nitrogen is used for solid transportation and feed dispersion.

For this study a constant feed rate of $2.5 \mathrm{~g} / \mathrm{min}$ of oil was used for all the tests. Total flow of nitrogen diluent towards the reactor was $156 \mathrm{Nml} / \mathrm{min}$, including flow for oil dispersion and solid carry-over. Three different reactors were used to attain different gas residence time ranges during operation. The gas residence time can be estimated from experimental data in the reactor with a correlation taking into account inlet composition, outlet composition, temperature and pressure in the reactor. Gas residence time shortened significantly at constant reactor volume when increasing the reaction temperature due to large increase in gas yield. Reactor diameter was maintained constant at $9 \mathrm{~mm}$, while length was 15,45 or $110 \mathrm{~cm}$, resulting 
in volumes of 10,30 and $70 \mathrm{~cm}^{3}$ approximately. Residence time varied in the range of 0.4 to 0.8 $\mathrm{s}$ for the short reactor, 1 to 2 seconds for the intermediate reactor and 2.5 to 5 seconds for the long reactor, depending on feed and processing temperature. Total pressure was kept at 0.5 bar above atmospheric pressure.

\subsection{Analysis of the cracked products and mass balance}

Gases were analyzed using a Varian 3800-GC equipped with three detectors, two Thermal Conductivity Detectors (TCD) for analysis of $\mathrm{H}_{2}$ and $\mathrm{N}_{2}$ after separation on a $15 \mathrm{~cm}$ column filled with $5 \mathrm{~A}$ and a $8 \mathrm{~cm}$ column filled with $13 \mathrm{X}$ molecular sieves respectively, and a Flame Ionization Detector (FID) for $C_{1}$ to $C_{6}$ hydrocarbons separated in a $30 \mathrm{~m}$ Plot/Alumina column. Simulated distillation of the liquids was carried out with a Varian 3800-GC following ASTM-D2887 procedure. Cuts were made at $216^{\circ} \mathrm{C}$ for gasoline and $359^{\circ} \mathrm{C}$ for diesel. The fraction with a boiling point above $359^{\circ} \mathrm{C}$ was defined as Bottoms. Coke was burned in situ and the resulting $\mathrm{CO}_{2}$ weight measured using adsorbents. Mass balances were considered acceptable in the range $100 \pm 5 \%$ of the feed introduced.

A conversion was defined as the sum of gases, gasoline, and coke. It has to be reminded here that this conventional definition is not very relevant when applied to the cracking of light fractions or crude oil that includes a significant amount of gasoline.

\section{Results and discussion}

\subsection{Thermal Cracking yields at constant gas residence time.}

For each feed and residence time, a factorial experimental plan was programmed with reaction temperature and catalyst to oil ratio as variables. The experimental plan is presented in Table S1. The solid to oil ratio range was adapted to each reaction temperature so that the preheat temperature for the solid remained into reasonable limits $\left(650-725^{\circ} \mathrm{C}\right)$ similar to those imposed in commercial Fluid Catalytic Cracking Unit regenerator.

The yields obtained with the $70 \mathrm{~cm}^{3}$ reactor when varying Solid to oil ratio (STO) and reaction temperature are shown in Figure 1. The gas residence time for these experiments was estimated in the 2-3 seconds range.

It was found that STO had no significant influence on yields, as could be expected from thermal cracking. Identical results were obtained with other feeds or residence time range. Thermal shock, which is higher with lower solid to oil ratio, had no noticeable contribution on yields, and was neglected for further modeling. This is also an indication that the vaporization at the feed-solid mixing point is fast in the laboratory unit reaching rapidly reactor temperature.

Only coke yield showed some response with varying Solid to oil ratio, with a slight increase when increasing STO, which may be due to some residual surface area of the solid used for testing. As a consequence for further thermal cracking modeling, coke yield was simulated as direct depositions on the solid from the heaviest fraction of the feed, with a yield equal to the Carbon Conradson (CCR) content. 
Thus, the influence of STO for the rest of the study was discarded, and the three remaining variables were reaction temperature, residence time and feed. The yields obtained at several solid to oil ratios were averaged to yield a single data corresponding to a particular reaction temperature, residence time and feed.

Figure 1. Thermal cracking yields against Solid-to-Oil ratio. AXL crude oil, 2-3 seconds contact time, and reaction temperature $560-640$ ㅇ C
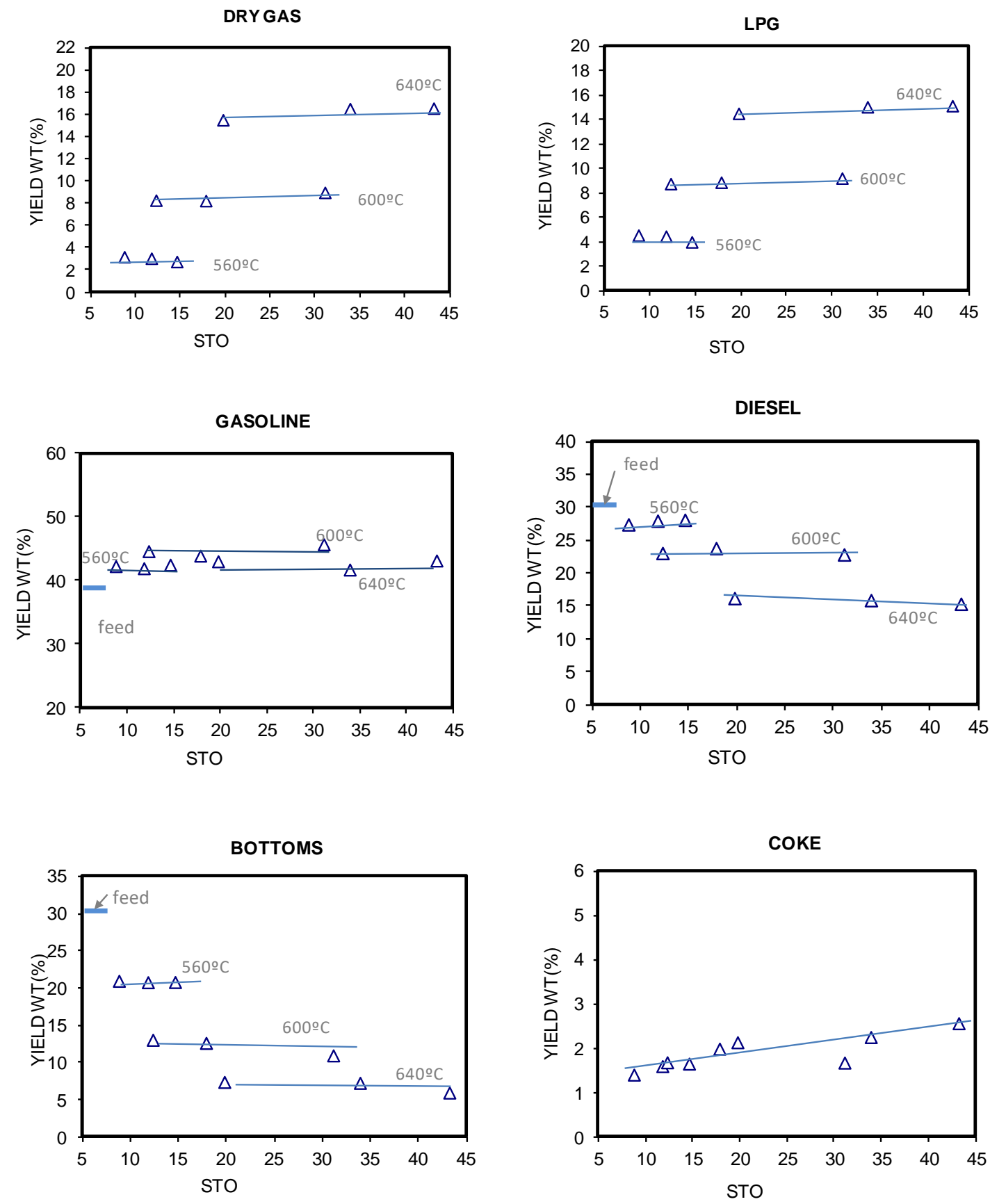


\subsection{Thermal cracking yields depending on residence time and temperature}

A 27 data set was then obtained from varying reaction temperature, residence time and feed. Yields are fully disclosed in Tables S2 to S4. Conversion as a function of residence time is presented in Figure 2. Figure 3 to Figure 5 reports main yields from thermal cracking of crude oil and its fractions.

Conversion was found higher for the lighter feeds due to a considerable amount of gasoline in the feed. Gas yields were found higher as the feed contains more heavy material, illustrating the increasing refractoriness to cracking of the lighter fractions. For the heavy fraction of the crude oil, conversion level also increased sharply with reactor temperature at constant residence time, ranging from $20 \%$ at $560{ }^{\circ} \mathrm{C}$ to $72 \%$ at $640{ }^{\circ} \mathrm{C}$ and 2 seconds time-onstream.

Bottoms conversion up to $80 \%$ could be obtained at 640 - $\mathrm{C}$ after $2-3$ seconds gas residence time, both with crude oil and heavy fraction of crude oil cracking (Figure 3 and Figure 5). At $560^{\circ} \mathrm{C}$ however, conversion remained limited below $30 \%$ after 2 seconds residence time. Diesel fraction converted to a lower extent, with a conversion level of $50-60 \%$ at the most severe conditions. At $560^{\circ} \mathrm{C}$, the conversion was rater limited. In the case of cracking the heavy fraction of the crude oil, the diesel consumption rate was nearly equaled by the production rate from the bottoms fraction, which resulted in a flat diesel yield profile over the first 3 seconds time onstream.

Gasoline yield behavior depends sharply on the relative reaction rate of gasoline production from heavier fractions and gasoline cracking. The reaction temperature, residence time, and the initial amounts of gasoline and heavier products in the feed will mainly influence these rates, hence the yield changes. For light fraction, at temperatures of 560 to $600 \circ \mathrm{C}$, gasoline disappearance rate remains low and is compensated by production from diesel fraction, so that yield barely evolves on the residence time scale. At higher temperature gasoline is more reactive and disappearance rate is no longer compensated by production rate from diesel cracking, so that gasoline yield decreases with residence time. For heavy fraction, gasoline yield continuously increases on the time scale due to the larger amount of heavy material and a lack of initial gasoline to be cracked. For the whole crude, a mixture of these behaviors is observed. Initially, the gasoline yield increases slightly as heavier material is being cracked. Then, gasoline yields passes a maximum around $1 \mathrm{~s}$ residence time at $640^{\circ} \mathrm{C}$ or $3-5 \mathrm{~s}$ at $600^{\circ} \mathrm{C}$, and then decreases. Maximum is not observed at $560^{\circ} \mathrm{C}$.

Coke yield was found constant with the time-on-stream, and showed a slight increase with the reaction temperature. This may however be due only to a change in solid to oil ratio, which tended to be much larger at higher reaction temperature, and may explain the slight increase in coke yield.

Detailed gas yields are displayed in Figures S1 to S3. Most components yields but butanes followed a curve pattern similar to that of total gas. Similarly large yields of ethylene and propylene were found, which is a major difference with catalytic cracking. Also, in the butenes fraction 1-butene is the major component while iso-butene is present in lower amounts. It is well known that thermal cracking favors alpha-olefins. Large amounts of methane, 
ethane and propane are also observed. The relatively high yield of butanes is explained by the n-butane feed content, which distort yield evolution with residence time. Isobutane yield is also affected, as the possible result of an equilibrium between $n$-butane and iso-butane. The iso to normal ratio observed ( 0.2 to 0.3 ) is yet significantly lower than predicted by thermodynamic equilibrium at this temperature $(0.43,[26])$. With the heavy crude oil fraction, which do not contain n-butane, much smaller yields were observed. The yield of propane and butane seems to increase with temperature at a lower rate than the yields of olefins, which suggest that the activation energy for the formation of these components is smaller than the activation energy for the rest of the gas components. All the gas components yields (but propane and butanes) seems to increase at a similar rate with the temperature increase from 560 to 640 으. Temperature and residence time in this study may not have been high enough to observe significant recracking of gas components. 
Figure 2. Conversion as a function of gas residence time for crude oil, light fraction and heavy fraction. Reaction temperature from 560 to 640 으. Zero residence time corresponds to the initial gasoline content of the feed.

AXL feed



Light, $C_{5}-350$ feed

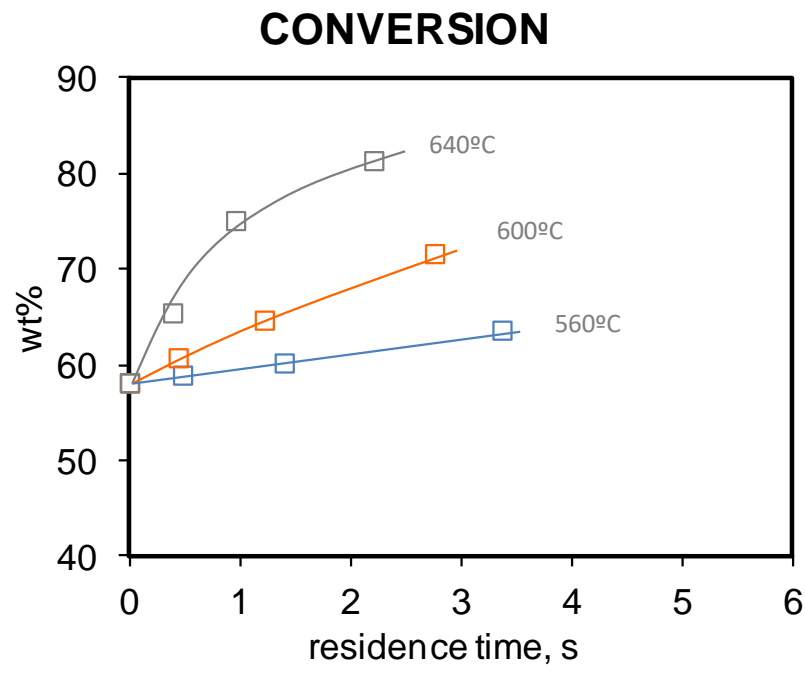

Heavy, 350+ feed

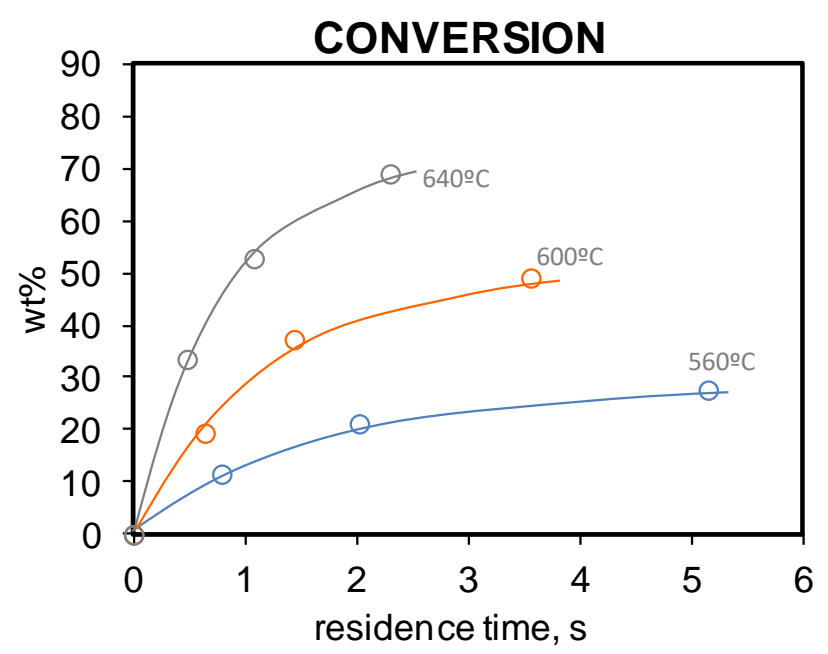


Figure 3. Main yields as a function of gas residence time for crude oil. Reaction temperature from $\mathbf{5 6 0}$ to 640 ․ C. Zero residence time corresponds to the initial composition.
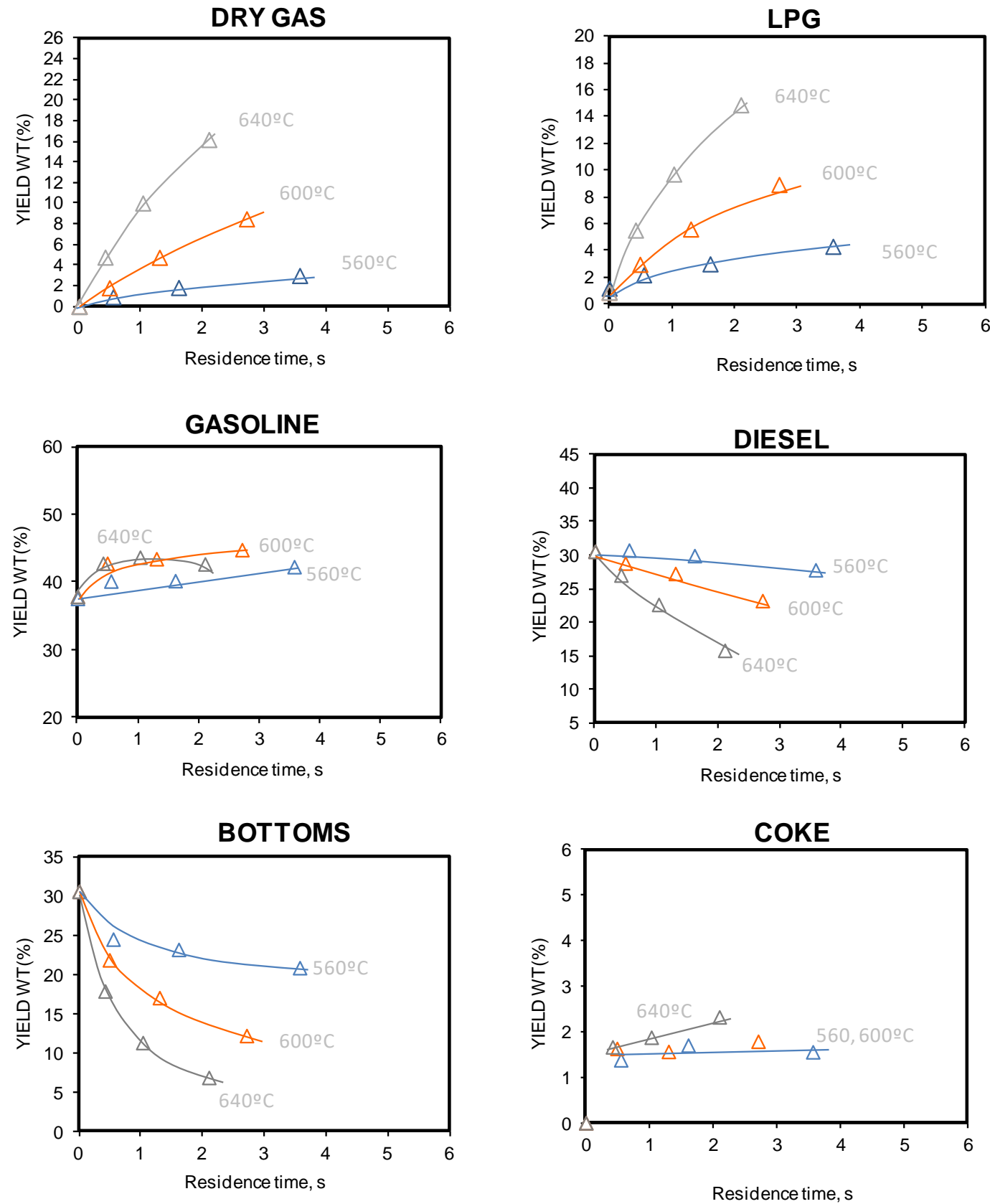
Figure 4. Main yields as a function of gas residence time for light crude oil fraction $\left(\mathrm{C}_{5}-3500^{\circ} \mathrm{C}\right)$.

Reaction temperature from 560 to 640 으. Zero residence time corresponds to the initial composition.
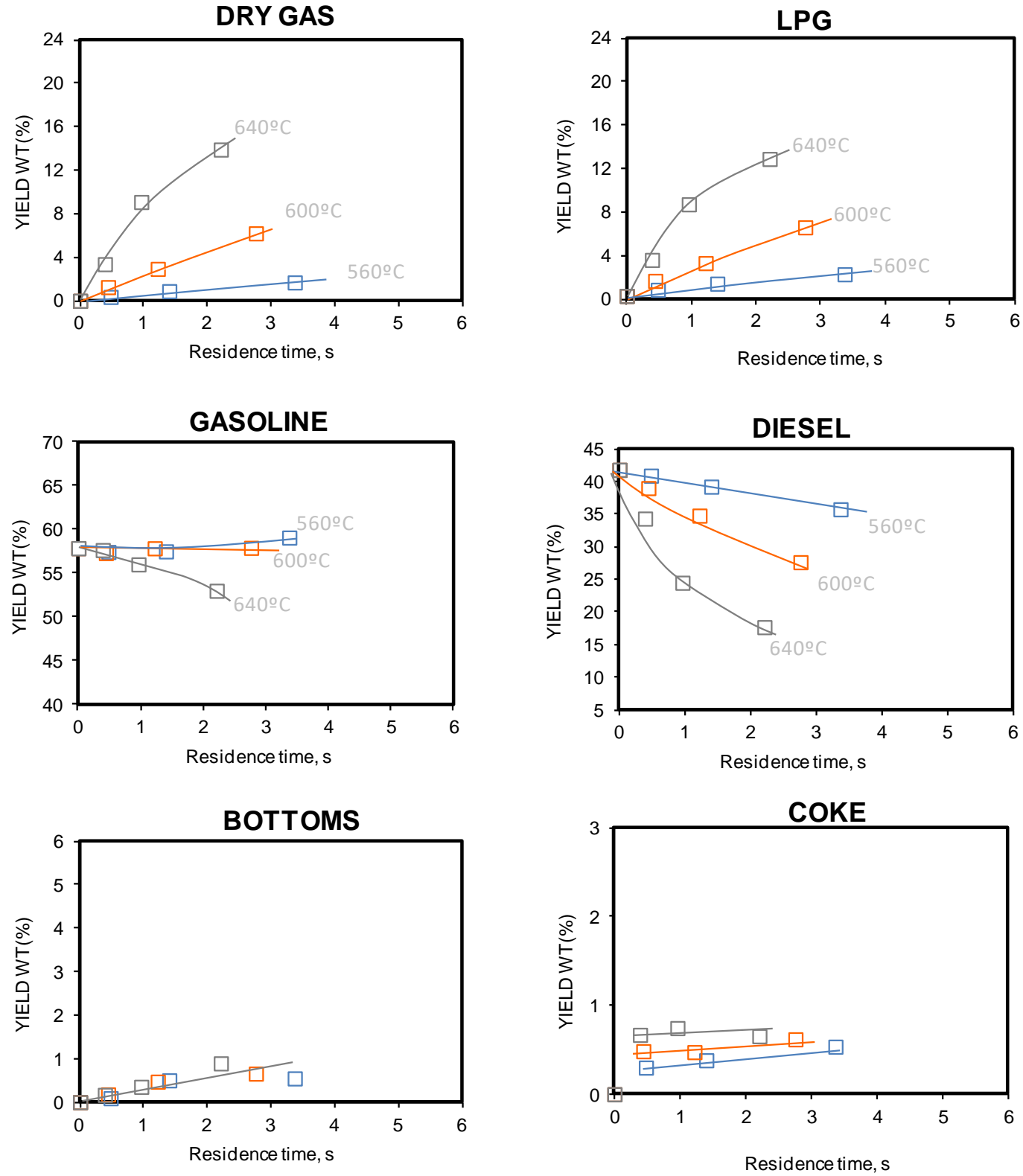
Figure 5. Main yields as a function of gas residence time with heavy fraction of the crude oil $(b p>350$ ㅇ $)$. Reaction temperature from 560 to 640 으. Zero residence time corresponds to the initial composition.
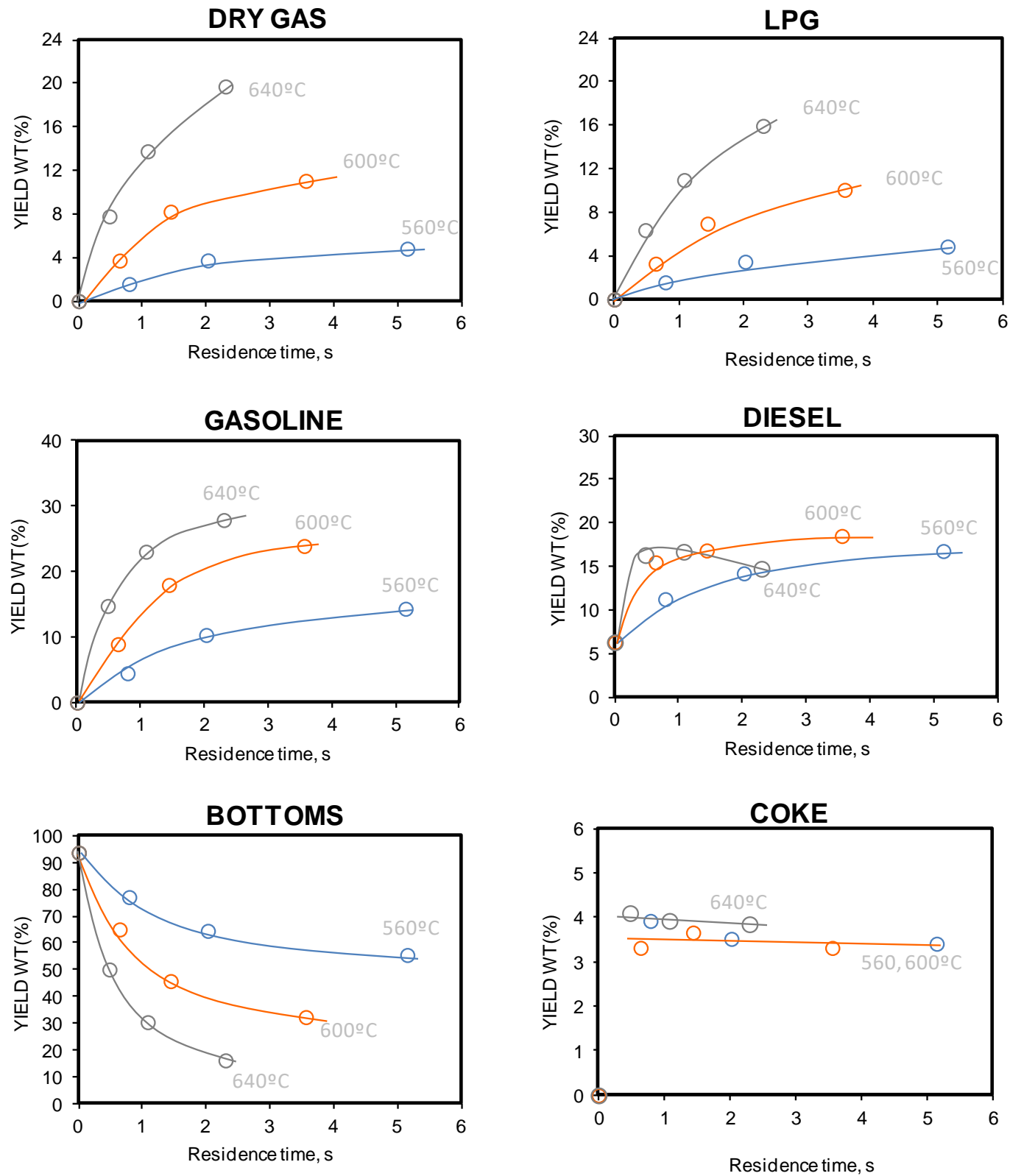


\section{Modeling and Kinetics constants}

\subsection{Model description}

\subsubsection{Hypothesis}

A number of assumptions were made for developing the kinetic model:

- Isothermal plug flow, feed is instantly and totally vaporized at the reactor inlet

- solid not taken into account as it occupies only a minor fraction of the volume and it is not catalytically active

- first order reaction rate with Arrhenius type cracking constants

- Coke formed by direct deposition from the heaviest fraction at the first solid and oil contact. Previous data showed no response of coke yield with contact time in the reactor under the time frame considered, so no in-reactor kinetic contribution can be calibrated.

- Activation energy increases when cracking lighter fractions and when the cracking product is lighter

\subsubsection{Reaction network, reaction rate and kinetic constant definition}

A model with 9 components was chosen to represent thermal cracking, with emphasis on gas composition. The considered lumps and components are: Dry gas (including hydrogen, methane and ethane), ethylene, Light Petroleum Gas (including propane and butanes), propene, butenes (including butadiene), gasoline, diesel, Vacuum Gas Oil (VGO) and coke. VGO fractions may also be referred by the term Bottoms following catalytic cracking terminology. General cracking network is presented in Figure 6a. A reduced model where the five gas components are grouped into a single gas lump (Figure $6 \mathrm{~b}$ ) is also used for fitting the main cracking constants. The formulation of the model was intentionally chosen to be similar to that of catalytic cracking models found in the literature to facilitate the integration of the present model with its catalytic counterpart in dual models.

The molar masses used for the different lumped component were, in $\mathrm{g} / \mathrm{mol}: 450$ for VGO lump, 226 for diesel lump, 100 for Gasoline lump, 30 for total gas lump, 50 for paraffins in LPG lump and 18 for Dry Gas lump (excluding ethylene). Molar masses corresponds to 16 and 32 carbons paraffins for the diesel and VGO lumps respectively. A few PIONA analyses were carried out to determine the most appropriate molar mass for gasoline, while that of gases was derived from detailed gas analysis. The resulting stoichiometry between lumps is very close to that used in other publications on catalytic cracking modeling [27].

First order reaction rate was chosen to model the reaction rate. A balance on an elemental volume $\mathrm{dV}$ of the reactor yields the following relationship between the derivate of molar flow $\mathrm{F}_{\mathrm{i}}$ and its reaction rate $r_{i}$ :

$$
\begin{array}{r}
\frac{\partial F_{i}}{\partial V}=r_{i}=\sum_{j} \alpha_{j} k_{j} C_{j} \\
\text { with } \quad k_{j}=k_{j}^{0} e^{\left(-\frac{E_{a i}}{R}\left(\frac{1}{T}-\frac{1}{T_{0}}\right)\right)}
\end{array}
$$

Molar coefficient $\alpha_{j}$ is the molar ratio between molar mass of reaction product $\mathrm{j}$ over molar mass of reactant $i$ which reaction rate is calculated, and reflects the gas expansion during cracking. $C_{i}$ is the molar concentration of compound $i, E_{a i}$ the activation energy corresponding to 
reaction $\mathrm{i}, \mathrm{T}$ the reaction temperature, $\mathrm{T}_{0}$ a reference temperature that in this case is taken at $600^{\circ} \mathrm{C}$, and $\mathrm{k}_{\mathrm{i}}{ }^{0}$ the kinetic constant at this reference temperature $T_{0}$. This formalism for kinetic constant avoids strong correlation between pre-exponential factor $A_{i}$ and activation energy $E_{a i}$ in the more traditional formulation: $k_{i}=A_{i} e^{\left(-\frac{E_{a i}}{R T}\right)}$ which may mislead optimization software. No deactivation function was implemented in thermal cracking.

Figure 6a. 9 lumps cracking network



Figure $6 \mathrm{~b}$. Reduced 5 lumps components for the determination of main rate constants $\mathbf{k} 1$ to $\mathrm{k} 6$

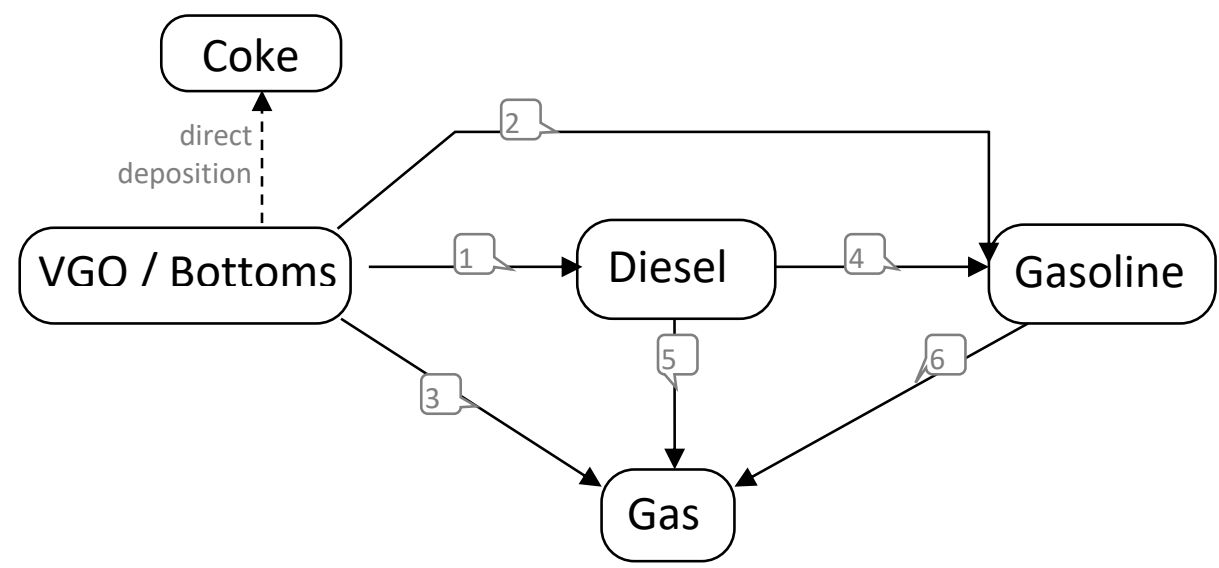

In view of the large number of parameters to be fitted (18 constants +18 activation energies), a number of additional assumptions were made to reduce the number of parameters to be estimated.

First, main selectivity from VGO lump cracking were determined directly from the experimental data obtained in the cracking of the heavy fraction of crude oil, which is mainly VGO (94\%). The heavy diesel present in this feed was considered to behave like VGO. Introducing 
the selectivity $s^{0}$ for gas, gasoline and diesel at the reference temperature $(600 \circ)$, and the global VGO cracking constant $\mathrm{k}^{0}{ }_{\mathrm{VGO}}$ at this same reference temperature, we have the relationship $k_{V G O}^{0}=\sum_{j} s_{j} k_{j}^{0}$ with $\mathrm{j}=1$ to 3 .

Yields of gas, gasoline and diesel were then plotted against conversion, as shown in Figure 7. Conversion was calculated as the sum of these three components and excluding coke, which is deposited directly when feed and solid comes into contact. The slope of the yield curve at conversion zero gives the initial selectivity for gas, gasoline and diesel from the VGO fraction at the selected temperature. Ideally, several points at very low conversion should be taken into account, but at 600 ㅇ $\mathrm{C}$ it was not possible to lower conversion below $20 \mathrm{wt} \%$. Also, activation energy was not determined because the lowest conversion obtained at 640 ㅇ $\mathrm{C}$ was about $40 \%$ for VGO, and thus the initial selectivity determined graphically at this temperature was considered not reliable. Thus, the selectivity at the reference temperature of $600{ }^{\circ} \mathrm{C}$ for VGO cracking towards diesel, gas and gasoline was set at $s^{0}{ }_{1}=0.3628, s_{2}{ }_{2}=0.3525$ and $s^{0}{ }_{3}=0.2847$ respectively, and the global kinetic constant for VGO cracking $\mathrm{k}^{0}{ }_{\mathrm{VGO}}$ will be fitted numerically.

Then, in order to decrease further the number of independent parameters to estimate, we assumed that the selectivity toward each gas component was similar from VGO, diesel or gasoline lumps. As the lower increase of LPG yield with temperature indicated a possible difference in activation energy for the gas components, the activation energy for each gas component was set as a parameter to optimize. Then, the kinetic constant for the formation of a gas component $\mathrm{i}$ from a lump $\mathrm{j}$ can be written as:

$$
\mathrm{k}_{\mathrm{ji}}=\mathrm{s}_{\mathrm{i}} \mathrm{k}_{\mathrm{j}}^{0} \mathrm{e}^{\left(-\frac{\mathrm{E}_{\mathrm{ai}}+\Delta \mathrm{E}_{\mathrm{aj}}}{\mathrm{R}}\left(\frac{1}{\mathrm{~T}}-\frac{1}{\mathrm{~T}_{0}}\right)\right)}
$$

with $\mathrm{s}_{\mathrm{i}}$ the selectivity to the gas component $\mathrm{i}$ ( $\mathrm{a}$ to e) and $\Delta \mathrm{E}_{\mathrm{ai}}$ the relative activation energy toward the compound $i$, by difference from the global gas activation energy $E_{a j}$ relative to the global cracking constant $k_{j}$ (eqn. 2, with $j=3,5$ or 6 , component $i$ formed from VGO, diesel or gasoline lump respectively). Also, the selectivity at the reference temperature is bound by the relation:

$$
s_{a}+s_{b}+s_{c}+s_{d}+s_{e}=1
$$

As stated before, coke was modeled as a deposit from the heaviest fraction present in the feed that builds readily during the initial contact between feed and solid, remaining then constant during the rest of the reaction. A component which yield remains nearly constant while the conversion changes from $11 \%(350+$ feed, 560 ㅇ $\mathrm{C}$ ) to $70 \%(350+$ feed, 640 으 $\mathrm{C}$ ) cannot be properly represented by the formulation presented in equation 1 . Thus, coke yield was set as:

0.3 wt \% coming from LCO fraction for light feed

$1.3 \mathrm{wt} \%$ coming from $\mathrm{HCO}$ fraction for $\mathrm{AXL}$

3.5 wt\% coming from $\mathrm{HCO}$ fraction for heavy $350+$ feed 
Figure 7. Graphical determination of initial VGO selectivity towards main lumps.


\subsubsection{Others considerations}

Gas residence time $\left(t_{\text {res }}\right)$ is calculated along the reactor of length $L$ as:

$$
t_{\text {res }}=\int_{0}^{L} S \frac{d x}{Q}
$$

with $\mathrm{S}$ the section of the reactor at point $\mathrm{x}$ and $\mathrm{Q}$ the flow at this point. Through kinetic model we can know the composition of the hydrocarbon gas mixture at every point of the reactor. Volumetric flow $Q$ is then calculated from the sum of the molar flow of the different components vaporized plus nitrogen diluent, divided by standard volume of one mole $(22.4 \mathrm{l} / \mathrm{mol})$ and taking into account local temperature and pressure.

For the resolution of concentration profile along the riser reactor a Runge-Kutta 4 algorithm has been used. Integration step was adapted to local reaction rate so that the conversion of the most abundant component was limited to $0.5 \%$ weight per step, with a maximum step length of $1 \%$ of total reactor length. The model parameters were estimated by using a non-linear least-square analysis according to Buzzi-Ferraris [28]. The objective function $f$ to be minimized was designed as the sum of squared residues between experimental mass yields $\mathrm{Y}_{\mathrm{i}, \mathrm{j}}$ of compound $\mathrm{i}$ obtained in the $\mathrm{j}$ experimental point with the computed value $\overline{Y_{i, j}}$ at the outlet of the reactor at the corresponding point:

$$
f=\sum_{i=1}^{N L} \sum_{j=1}^{N C}\left(Y_{i, j}-\overline{Y_{l, j}}\right)^{2}
$$

where NL is the number of lumps considered in the reaction scheme, and NC the number of experimental points considered.

\subsection{Fitted model parameters}


First, the kinetic constant towards the main lumps were fitted, and results are shown in Table 4. Reaction rate constants values are given at $600^{\circ} \mathrm{C}$. Model predictions were compared with experimental data in Figure 8. In general, the agreement between experimental data and model predictions are good. The thermal cracking rate of VGO to products at $600{ }^{\circ} \mathrm{C}$ was found to be twice that of diesel fraction and around 10 times that of gasoline. Diesel selectivity to gas and gasoline was found to be similar, slightly higher towards the former.

Activation energies were found in the $140-200 \mathrm{~kJ} / \mathrm{mol}$ range, which is typical from thermal cracking. Note that the diesel to gasoline activation energy was constrained by the system to be equal or higher than the activation energy from VGO to gasoline.

While VGO cracking parameters were obtained with a good confidence interval for both the rate constant and activation energy, the other parameters presented a large confidence interval, of the same order of magnitude than the determined constants, which means they are of low significance in the model. This is due to the minor contribution of these reactions to the global yields (for the much lower rate constant leading to much smaller reaction rate), so that the influence of these parameters on the system are much lower than the contributions from VGO, hence the larger confidence interval.

In comparison, typical activation energies for catalytic cracking are in the $10-50 \mathrm{~kJ} / \mathrm{mol}$ range [14]-[17]. Activation energies reported for catalytic pyrolysis were more similar, in the 80$200 \mathrm{~kJ} / \mathrm{mol}$ range [21]. Reactions which were catalyzed presented an activation energy in the intermediate $80-120 \mathrm{~kJ} / \mathrm{mol}$ range, as these values integrated both catalytic and thermal contributions. By the contrary, reactions that occur mainly through thermal cracking such as dry gas production had activation energy very similar to those reported in the present study.

These values were then fed to the 9 lump model and the selectivity to gas components was fit. Results are summarized in Table 5 . Selectivity values are given at $600^{\circ} \mathrm{C}$. The selectivity towards ethylene and propylene were very similar, somewhat lower toward butenes and slightly higher towards dry gas. Selectivity to LPG was much lower, as was expected from the experimental yields. The relative activation energy for all the gas components but LPG were close to zero, which means that the response to the temperature change of the kinetic rate constant for all components (but LPG) are similar. Meanwhile, LPG response to temperature is much lower than the other gas components. With an activation energy towards gas lump between 170 and $200 \mathrm{~kJ} / \mathrm{mol}$, LPG activation energy lies in the 90 to $120 \mathrm{~kJ} / \mathrm{mol}$. Confidence intervals were good for these values. 
Table 4. Kinetic parameters relative to main lumps (VGO, diesel, gasoline and gas). Optimized values are given with $95 \%$ confidence interval. Kinetic constants $k_{i}$ are given at $600 \circ \mathrm{C}$

\begin{tabular}{|cccc|}
\hline Reaction & Parameter & unit & Optimized value $\left(\mathrm{k}_{\boldsymbol{i}} \times \mathbf{1 0}^{3}\right)$ \\
\hline VGO to products & $\mathrm{k}^{0}{ }_{\text {gasoil }}$ & $\mathrm{s}^{-1}$ & $343( \pm 15)$ \\
Diesel to gasoline & $\mathrm{k}^{0}{ }_{4}$ & $\mathrm{~s}^{-1}$ & $76( \pm 49)$ \\
Diesel to gas & $\mathrm{k}_{5}{ }_{5}$ & $\mathrm{~s}^{-1}$ & $86( \pm 52)$ \\
Gasoline to gas & $\mathrm{k}^{0}{ }_{6}$ & $\mathrm{~s}^{-1}$ & $38( \pm 35)$ \\
\hline VGO to diesel & $\mathrm{Ea}_{1}$ & $\mathrm{~kJ} \cdot \mathrm{mol}^{-1}$ & $142( \pm 18)$ \\
VGO to gasoline & $\mathrm{Ea}_{2}$ & $\mathrm{~kJ} \cdot \mathrm{mol}^{-1}$ & $154( \pm 21)$ \\
VGO to gas & $\mathrm{Ea}_{3}$ & $\mathrm{~kJ} \cdot \mathrm{mol}^{-1}$ & $169( \pm 28)$ \\
diesel to gasoline & $\mathrm{Ea}_{4}$ & $\mathrm{~kJ} \cdot \mathrm{mol}^{-1}$ & $154( \pm 144)$ \\
Diesel to gas & $\mathrm{Ea}_{5}$ & $\mathrm{~kJ} \cdot \mathrm{mol}^{-1}$ & $180( \pm 132)$ \\
Gasoline to gas & $\mathrm{Ea}_{6}$ & $\mathrm{~kJ} \cdot \mathrm{mol}^{-1}$ & $199( \pm 168)$ \\
\hline
\end{tabular}

Table 5. Selectivity to gas components and relative activation energy

\begin{tabular}{|cccc|}
\hline Reaction to & Parameter & unit & Optimized value \\
\hline Ethylene & $\mathrm{S}_{\mathrm{a}}$ & - & $0.229( \pm 0.011)$ \\
Propylene & $\mathrm{s}_{\mathrm{b}}$ & - & $0.221( \pm 0.010)$ \\
Butenes & $\mathrm{s}_{\mathrm{c}}$ & - & $0.179( \pm 0.010)$ \\
LPG & $\mathrm{s}_{\mathrm{d}}$ & - & $0.082( \pm 0.009)$ \\
Dry Gas* & $\mathrm{S}_{\mathrm{e}}$ & - & $0.289( \pm 0.010)$ \\
\hline Ethylene & $\Delta \mathrm{Ea}_{\mathrm{a}}$ & $\mathrm{kJ} \cdot \mathrm{mol}^{-1}$ & $6( \pm 5)$ \\
Propylene & $\Delta \mathrm{Ea}_{\mathrm{b}}$ & $\mathrm{kJ} \cdot \mathrm{mol}^{-1}$ & $1( \pm 5)$ \\
Butenes & $\Delta \mathrm{Ea}_{\mathrm{c}}$ & $\mathrm{kJ} \cdot \mathrm{mol}^{-1}$ & $-5( \pm 6)$ \\
LPG & $\Delta \mathrm{Ea}_{\mathrm{d}}$ & $\mathrm{kJ} \cdot \mathrm{mol}^{-1}$ & $-77( \pm 14)$ \\
Dry Gas & $\Delta \mathrm{Ea}_{\mathrm{e}}$ & $\mathrm{kJ} \cdot \mathrm{mol}^{-1}$ & $-4( \pm 4)$ \\
\hline
\end{tabular}

*by difference 
Figure 8. Thermal cracking conversion and main products yields - Experimental (dots) compared to simulated data (lines) obtained at different gas residence times and temperatures processing the whole AXL crude and its fractions.

Figure 9. Thermal cracking detailed gas yields - Experimental (dots) compared to simulated data (lines) obtained at different gas residence times and temperatures processing the whole AXL crude and its fractions.
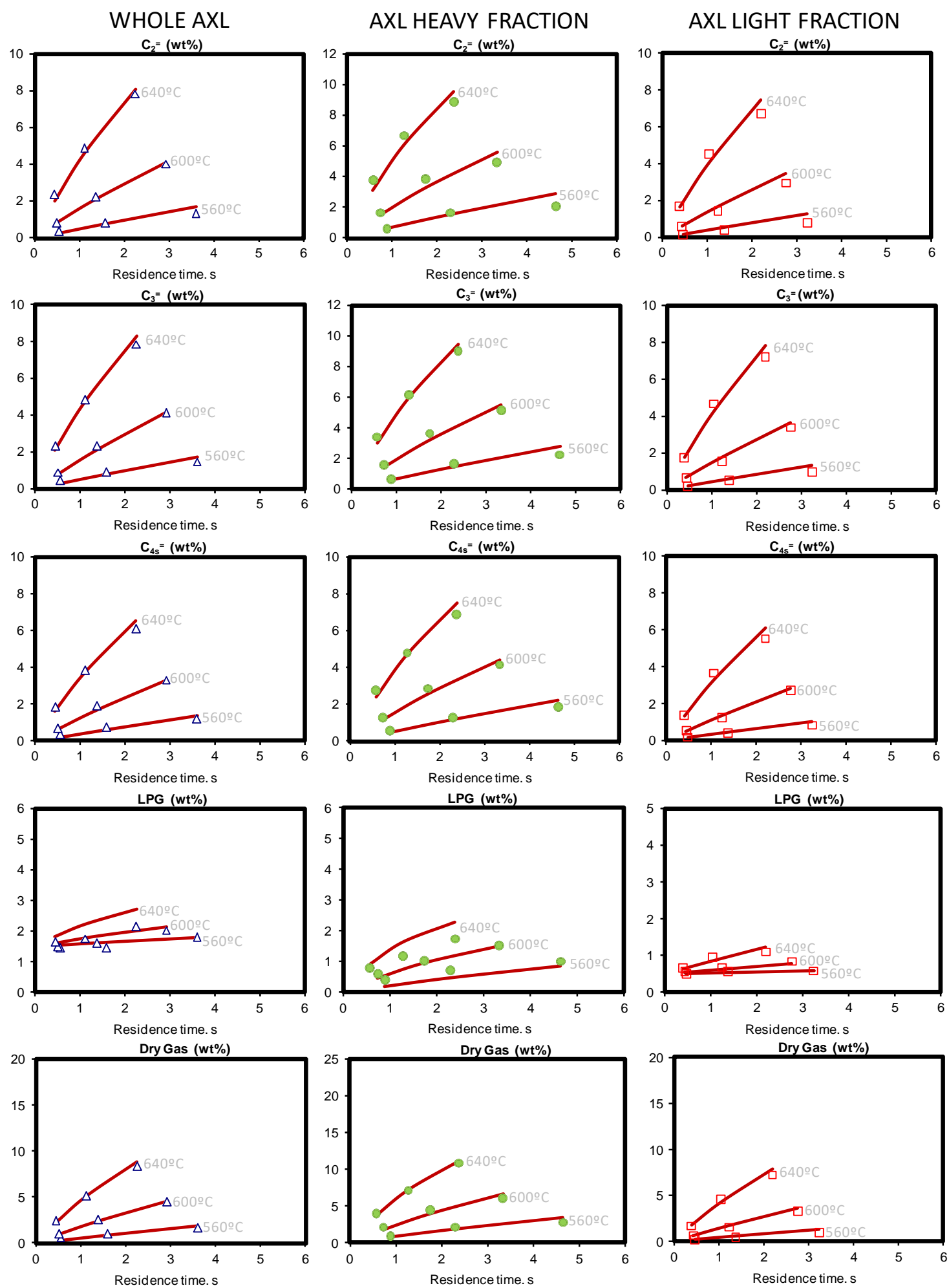


\subsection{Limits of the model}

At very high conversion the heavy and middle distillate fractions generally do become very aromatic in nature. It is thus expected that their thermal cracking rate and selectivity changes at very high conversion. Thermal cracking rate may decrease as aromatic molecules are more refractory. Also, selectivity to small gas components is expected to increase together with a significant coke formation, especially from polynuclear aromatics [28].

\section{Conclusions}

The possibility to directly crack crude oils in the Micro-Downer Unit has been presented. Thermal cracking of crude oil fractions was important at elevated temperatures, with a conversion of VGO-range fraction that can reach $80 \mathrm{wt} \%$ at $640^{\circ} \mathrm{C}$ in 2 seconds residence time. At this temperature, products are equally distributed between diesel, gasoline and gas fragments. Diesel also suffers considerable conversion, while gasoline only converts significantly at $640^{\circ} \mathrm{C}$. Dry gas (excluding ethylene), ethylene, propylene and butenes are formed in similar weight amounts. Total yields of $\mathrm{C}_{2}$ to $\mathrm{C}_{4}$ olefins up to $22 \%$ at 640 으 $\mathrm{C}$ were observed, with the remaining dry gas yield below $9 \mathrm{wt} \%$. The temperature and time range was too small to observe a significant formation of coke from secondary reaction between cracking products. VGO was found to thermally convert twice as fast as diesel and 10 times faster than gasoline, with high activation energy in the $140-200 \mathrm{~kJ} / \mathrm{mol}$ range.

\section{Acknowledgements}

The authors thank Saudi Aramco for its material and financial support. Financial support by the Spanish Government-MINECO through programs "Severo Ochoa" (SEV 2012-0267) and CTQ2015-70126-R and by the Generalitat Valenciana through the Prometeo program (PROMETEOII/2013/011) is also acknowledged.

\section{Bibliography}

[1] Sundaram KM, Shreehan MM, Olszewski EF. Ethylene. In: Kirk-Othmer Encyclopedia of Chemical Technology, volume 9. 4th ed. New York: John Wiley \& Sons, Inc. 1994, p. 877-915.

[2] Chauvel A, Lefebvre G. Petrochemical processes, Paris: Technip, 1989

[3] Dharia D, Letzsch W, Kim H, McCue D, Chapin L. Increase light olefins production. Hydrocarbon Process 2004;83(4):61-66

[4] Xieqing W, Chaogang X, Zaiting L, Genquan Z. Catalytic Processes for Light Olefin Production. In: Hsu CS, Robinson P, editors. Practical advances in Petroleum Processing, New York: Spinger-Verlag, 2006, p. 149-168

[5] Hiltunen J, Niemi VM, Lipiäinen K, Eilos I, Hagelberg P, Knuuttila P, Jääskeläinen K, Majander J, Röppänen J. NExCC - novel short contact time catalytic cracking technology. Stud Surf Sci Catal 2001;134:111-132.

[6] Ma'adhah A, Fujiyama Y, Redhwi H, Abul-Hamayel M, Aitani A, Saeed M, Dean C. A new catalytic cracking process to maximize refinery propylene. Arab J Sci Eng 2008;33(1B):17 
[7] Hu YC. Unconventional olefin processes Part 1: Crude/residual oil cracking. Hydrocarbon Process 1982;61(11):109-116.

[8] Schmalfeld P. How Lurgi improved sand crackers. Hydrocarbon Process Pet Refiner 1963;42(7):145148

[9] Kunii D. Chemical reaction engineering and research and development of gas solid systems. Chem Eng Sci 1980;35:1887-1910.

[10] Corma A, Corresa E, Mathieu Y, Sauvanaud L, Al-Bogami S, Al-Ghrami MS, Bourane A. Crude oil to chemicals: light olefins from crude oil. Catal Sci Technol 2017;7:12

[11] Weekman VW, Nace DN. Kinetics of catalytic cracking selectivity in fixed, moving, and fluid bed reactors. AIChE J 1970;16:397

[12] Jacobs SM, Gross B, Voltz SE, Weekman VW. A lumping and reaction scheme for catalytic cracking. AIChE J 1976;22:701-713

[13] Viner, MR, Wojciechowski BW. The chemistry of catalyst poisoning and the time on stream theory. Can J Chem Eng 1982;60:127-135

[14] Van Landeghem F, Nevicato D, Pitault I, Forissier M, Turlier P, Derouin C, Bernard JR. Fluid catalytic cracking: modeling of an industrial riser. Appl Catal A 1996;138:381-390

[15] Dewachtere NV, Froment GF, Vasalos I, Markatos N, Skandalis N. Advanced modeling of riser-type catalytic cracking reactors. Appl Thermal Eng 1997;17:837-844

[16] Corma A, Melo FV, Sauvanaud L. Kinetic and decay cracking model for a MicroDowner unit. Appl Catal A 2005;287:34-46

[17] Christensen G, Apelian MR, Hickey KJ, Jaffe SB. Future directions in modeling the FCC process: an emphasis on product quality. Chem Eng Sci 1999;54:2753-2764

[18] Abul-Hamayel MA. Kinetic modeling of high-severity fluidized catalytic cracking. Fuel 2003;82:1113-1118

[19] Liu Y, Chen X, Zhao H, Yang C. Establishment of kinetic model for catalytic pyrolysis of Daqing atmospheric residue. Chin J Chem Eng 2009;17(1):78-82

[20] Meng XH, Xu CM, Li L, Gao JS. Studies on the Kinetics of Heavy Oil Catalytic Pyrolysis. Ind Eng Chem Res 2003;42:6012-6019

[21] Meng XH, Xu CM, Gao JS, Li L. Catalytic pyrolysis of heavy oils: 8-lump kinetic model. Appl Catal A 2006;301:32-38

[22] Meng X, Xu C, Gao J, Li L. Studies on catalytic pyrolysis of heavy oils: Reaction behaviors and mechanistic pathways. Appl Catal A 2005;294:168-176

[23] Dente M, Ranzi E, Goossens AG. Detailed prediction of olefins yields from hydrocarbon pyrolysis through a fundamental simulation model (SPYRO). Comput. Chem. Eng. 1979;3:61-75

[24] Corma A, Melo FV, Martinez C, Sauvanaud L, Carriat JY. A new continuous laboratory reactor for the study of catalytic cracking. Appl Catal A 2002;232:247-263

[25] Corma A, Sauvanaud L, Melo FV. Test unit for studying catalysts in reactions involving a short contact time between the catalyst and the reagents. World Pat. $\mathrm{n}=03043726,2003$, assigned to UPV-CSIC (Spain).

[26] Rossini FD, Prosen EJR, Pitzer KS. Free energies and equilibria of isomerization of the butanes, pentanes, hexanes and heptanes. J Res Natl Bur Stand 1941;27:529-541

[27] Corella J, Frances E. Analysis of the riser reactor of a fluid cracking unit. Model based on kinetics of cracking and deactivation from laboratory tests. ACS Symp Ser 1991;452:165-82

[28] Buzzi-Ferraris G. Metodo automatico per trovare l'ottimo di una funzione. Ing Chim Ital 1968;4(12):171-190

[29] Kopinke F-D, Zimmermann G, Reyniers GC, Froment GF. Relative rates of coke formation from hydrocarbons in steam cracking of naphtha. 3. Aromatic hydrocarbons. Ind Eng Chem Res 1993;32:2620-2625 